\title{
ANALISIS TINGKAT RISIKO KEBAKARAN WILAYAH JAKARTA UTARA, PROVINSI DKI JAKARTA
}

\author{
Sekarsari Kartika Putri ${ }^{1}$, Fatma Lestari ${ }^{2}$, Miranda Surya Wardhany ${ }^{3}$ \\ Departmen Keselamatan dan Kesehatan Kerja, Fakultas Kesehatan Masyarakat Universitas Indonesia, ${ }^{1,2}$ \\ Disaster Risk Reduction Center, Universitas Indonesia (DRRC UI), Gedung Pusat Laboratorium ${ }^{2,3}$ \\ skputri08@gmail.com ${ }^{1, f a t m a @ u i . a c . i d ~}{ }^{2}$
}

\begin{abstract}
DKI Jakarta Province as the capital city of Indonesia is experiencing the surge of population up to 10.652 million people in 2021 and the region of North Jakarta has 11.272 people/km ${ }^{2}$ of population density. Not only the settlement that become more and more dense, North Jakarta flourished with the establishment of industrial area in Cilincing, recreational, warehousing and shopping area. The aim of this research is to find out the level of fire risk and to map the fire risk of North Jakarta in purpose to make improvement of fire prevention. The method used in this research is Cross Sectional with Non Probabilistic /Stratified Sampling approach. Data sampling done by online questionnaires and by discussion through Focus Group Discussion along with Local Fire Department of North Jakarta Region. Questionnaires consist of 3 elements and 22 variables which include the hazard identification, vulnerability and fire protection management. The collected data is used to make analysis using univariate, spider map and mapped to North Jakarta region. The result of the research shows the fire risk level of North Jakarta is Medium with score of 58,34\%. The improvements that can be done in order to prevent and countermeasure in North Jakarta are socialization about non flammable building materials and also the improvement and maintenance of city hydrants so they can be used effectively in supporting fire extinguishing in North Jakarta region. Furthermore it need to do some planning of fire detection system at settlement or public housing so it can be discovered and handled as fast as possible by Local Fire Department of North Jakarta Region.
\end{abstract}

Keyword $\quad$ : DKI Jakarta, Fire Mapping, Fire Risk Level, North Jakarta

\begin{abstract}
ABSTRAK
Provinsi DKI Jakarta sebagai Ibukota Negara mengalami peningkatan jumlah penduduk mencapai 10,562 juta jiwa pada tahun 2021 dan wilayah Jakarta Utara memiliki tingkat kepadatan penduduk 11.272 jiwa $/ \mathrm{km}^{2}$. Tidak hanya pemukiman penduduk yang semakin padat, Jakarta Utara berkembang dengan adanya Kawasan Berikat Nusantara Cilincing serta terdapat kawasan wisata, pergudangan maupun perbelanjaan. Tujuan penelitian adalah untuk mengetahui tingkat risiko kebakaran dan membuat pemetaan wilayah Jakarta Utara agar dapat dilakukan upaya perbaikan dan pencegahan kejadian kebakaran. Metode penelitian yang digunakan pada penelitian ini adalah Cross Sectional dengan pendekatan non probabilistic sampling/stratified sampling. Pengambilan data secara online kuesioner serta pelaksanaan diskusi melalui Focus Group Discussion bersama Dinas Pemadam Kebakaran Suku Dinas Jakarta Utara. Kuesioner terdiri dari 3 elemen dan 22 variabel yang mencakup identifikasi potensi bahaya, vulnerability serta manajemen proteksi kebakaran untuk selanjutnya dilakukan analisis menggunakan univariate, spider map dan dipetakan pada wilayah Jakarta Utara. Hasil penelitian menunjukkan tingkat risiko kebakaran wilayah Jakarta Utara adalah Sedang dengan nilai sebesar 58,34\%. Peningkatan yang dapat dilakukan pada upaya pencegahan dan penanggulangan kebakaran di Jakarta Utara adalah perlu dilakukan sosialisasi terkait penggunaan material bangunan yang tidak mudah terbakar serta adanya peningkatan fungsi dan pemastian pemeliharaan dari hidran kota yang dimiliki agar dapat digunakan secara efektif untuk mendukung upaya pemadaman kebakaran di wilayah Jakarta Utara. Selain itu perlu dilakukan perancangan sistem deteksi kebakaran pada rumah penduduk agar dapat diketahui dan ditangani dengan cepat oleh Dinas Pemadam Kebakaran Suku Dinas Jakarta Utara.
\end{abstract}

Kata Kunci : DKI Jakarta, Jakarta Utara, Peta Kebakaran, Tingkat Risiko Kebakaran 


\section{PENDAHULUAN}

Kebakaran merupakan salah satu bencana yang mengancam dan mengganggu kehidupan masyarakat. Kejadian kebakaran sering kali tidak terduga dan menimbulkan kepanikan karena ketidaksiapan masyarakat menghadapi bahaya kebakaran. Salah satu permasalahan pada negara berkembang adalah kejadian kebakaran pada pemukiman padat penduduk dimana korban jiwa seringkali ditemukan pada rumah tempat awal mula api terjadi dikarenakan keterlambatan proses pemadaman serta tidak dapat melakukan evakuasi dan penyelematan tepat waktu (Natalia Flores Quiroz, Richard Walls, Antonio Cicione, 2021). Tanggap darurat bencana dalam hal ini kebakaran merupakan seluruh kegiatan untuk mengurangi dampak buruk yang ditimbulkan dari bencana meliputi upaya penyelamatan dan evakuasi korban, harta benda, pemadaman serta pemulihan sarana prasarana (BNPB, 2007).

Kejadian kebakaran pada wilayah Provinsi DKI Jakarta tahun 2020 sebanyak 1.505 kasus dengan 983 kasus disebabkan dari konsleting listrik, 180 kasus dari kebocoran gas yang digunakan pada kompor dan peledakan serta adanya 43 kasus yang disebabkan dari penggunaan lilin dan pembuangan puntung rokok yang masih menyala (Unit Pengelola Statistik Provinsi DKI Jakarta, 2021). Wilayah Jakarta Utara memiliki 257 kasus kebakaran pada 2020 dan terjadi penurunan dari sebelumnya 337 kasus pada tahun 2019 (Portal Data Terpadu Pemprov DKI Jakarta, 2021). Hal ini sesuai dengan gambar peristiwa kebakaran setiap bulannya pada tahun 2019 dan 2020.1 Bangunan rumah menjadi tempat kejadian kebakaran terbesar pada tahun 2020 di Provinsi DKI Jakarta dengan 461 kasus, diikuti kebakaran pada instalasi diluar bangunan dengan 438 kasus dan bangunan umum serta perdagangan terjadi pada 269 kasus (Unit Pengelola Statistik Provinsi DKI Jakarta, 2021). Sebagian besar penyebab kebakaran pada bangunan rumah adalah aktifitas memasak, instalasi listrik, peralatan yang menimbulkan panas, penggunaan material yang mudah terbakar dan adanya aktifitas pembakaran (Ahrens and Maheshwari, 2020).

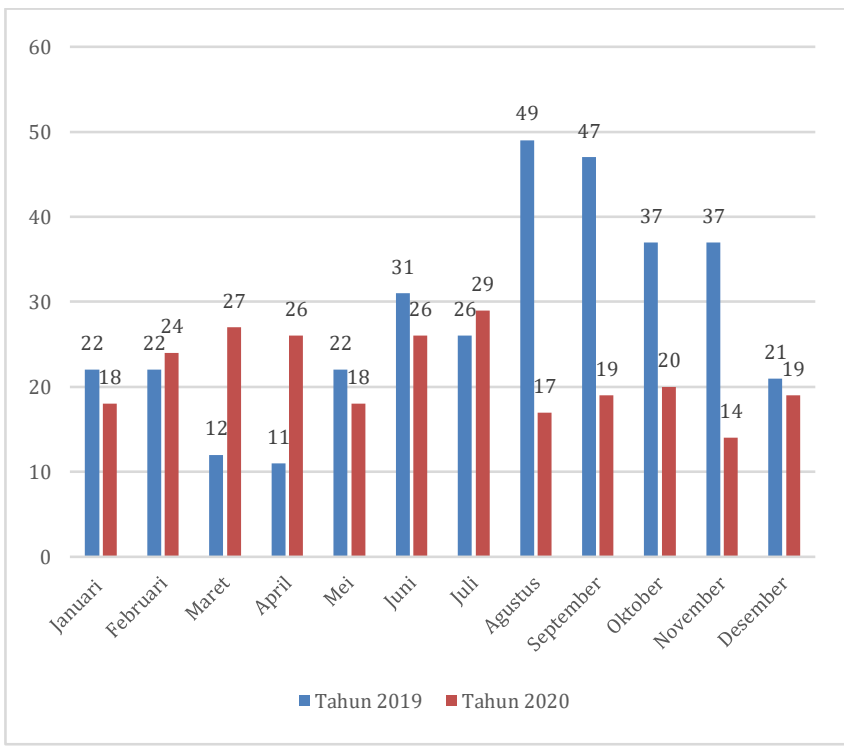

Gambar 1. Peristiwa Kebakaran Wilayah Jakarta Utara Tahun 2019 dan 2020

Pelaksanaan pemetaan kebakaran memiliki peran penting untuk mengindikasikan karakteristik suatu wilayah yang memiliki potensi besar terjadinya kebakaran dan membuat program pencegahan kebakaran berkelanjutan. Selain itu dapat melihat trend peningkatan kejadian kebakaran agar dapat mencegah kebakaran di masa yang akan datang serta mengontrol kebakaran sehingga tidak menimbulkan kerugian yang besar (Luo Yi Xin et al, 2021). Oleh karena itu menjadi kebutuhan suatu wilayah untuk melakukan penilaian dan pemetaan tingkat risiko kebakaran sebagai upaya pencegahan dan penanggulangan kebakaran di Jakarta Utara.

\section{METODE}

Penelitian ini menggunakan metode cross sectional dengan non probabilistic stratified sampling dan pengambilan data dilakukan sejak April hingga Juli 2021. Data awal merupakan pengisian kuesioner secara online oleh seluruh ketua Rukun Warga (RW) pada wilayah Jakarta Utara dan divalidasi melalui Focus Group Discussion dengan perwakilan 
Dinas Pemadam Kebakaran (Damkar) yang bertugas di Suku Dinas Jakarta Utara.

Terdapat 6 sektor pengambilan data dengan total $30 \mathrm{RW}$ dari 27 kelurahan. Sektor 1 meliputi kelurahan Marunda, Semper Barat, Rorotan, Kalibaru dan Semper Timur, Sektor 2 meliputi kelurahan Lagoa, Rawa Badak Selatan, Koja, Tugu Selatan, Rawa Badak Selatan dan Tugu Utara, Sektor 3 meliputi kelurahan Papanggo, Sunter Agung, Sungai Bambu, Sunter Jaya dan Tanjung Priok, Sektor 4 meliputi kelurahan Pegangsaan Dua dengan data dari 2 RW, Kelapa Gading Barat dengan data dari 2 RW dan Kelapa Gading Timur dengan data dari $2 \mathrm{RW}$, Sektor 5 meliputi Ancol, Pademangan dan Pademangan Timur serta Sektor 6 meliputi kelurahan Kamal Muara, Kapuk Muara, Pejagalan, Penjaringan dan Pluit.

Penelitian menggunakan instrumen yang terdiri dari 3 elemen dan 22 variabel. Elemen Hazard meliputi variabel dengan kategori terkait aktifitas masyarakat di wilayah tersebut yang dapat memicu terjadinya kebakaran, adanya penggunaan listrik yang menyebabkan kebakaran, adanya penggunaan api yang terbuka serta pengamatan terkait penggunaan Bahan Berbahaya dan Beracun. Elemen Vulnerability meliputi variabel tingkat kepadatan penduduk, kerapatan bangunan, kualitas dari bangunan serta tingkat kekumuhan lingkungan, seberapa besar frekuensi kejadian kebakaran, berapa besar luas area dan kerugian yang dialami, pengamatan kualitas bangunan dan perambatan api serta kendala yang dihadapi oleh Pos Damkar. Elemen Manajemen Proteksi Kebakaran meliputi pengamatan mengenai jarak pemisah setiap bangunan, penerapan sistem ketahanan kebakaran lingkungan serta partisipasi masyarakat maupun relawan kebakaran, efektifitas penggunaan komunikasi darurat, efektifitas sarana proteksi untuk pelaksanaan pemadaman dini, kelaikan Pos Damkar yang dimiliki wilayah Jakarta Utara, akses operasional Pos Damkar, waktu tanggap Pos Damkar, pelayanan Pos Damkar terhadap seluruh sektor, operasional pemadaman lanjutan hingga ketersediaan sumber air pemadaman, kemudahan akses pemadaman serta kondisi kelaikan dari hidran kota. Nilai pada setiap variabel adalah dari 1 - 5 dengan hasil total penilaian, semakin tinggi nilainya maka tingkat potensi bahaya kebakarannya semakin besar. Total skor akan dikalkulasikan dan menjadi 5 klasifikasi yaitu sangat rendah $(<20 \%)$, rendah $(21-40 \%)$, sedang $(41-60 \%)$, berat $(61-80 \%)$ dan sangat berat $(>80 \%)$. Data yang telah dikumpulkan pada saat penelitian, dilakukan uji risiko semikuantitatif menggunakan sistem informasi geografis dengan univariate analysis dan dijabarkan dengan grafik serta dipetakan menggunakan Spider Map dan digabungkan pada peta tingkat risiko wilayah Jakarta Utara.

\section{HASIL}

Hasil penelitian pada wilayah Jakarta Utara terdiri dari Sektor 1 memiliki rata-rata nilai $51,3 \%$, sektor 2 memiliki rata-rata nilai $58,2 \%$, sektor 3 memiliki rata-rata nilai $57,3 \%$, sektor 4 memiliki rata-rata nilai $53,9 \%$, sektor 5 memiliki rata-rata nilai $61,2 \%$ dan sektor 6 memiliki rata-rata nilai $68,2 \%$ sebagaimana gambar berikut ini :

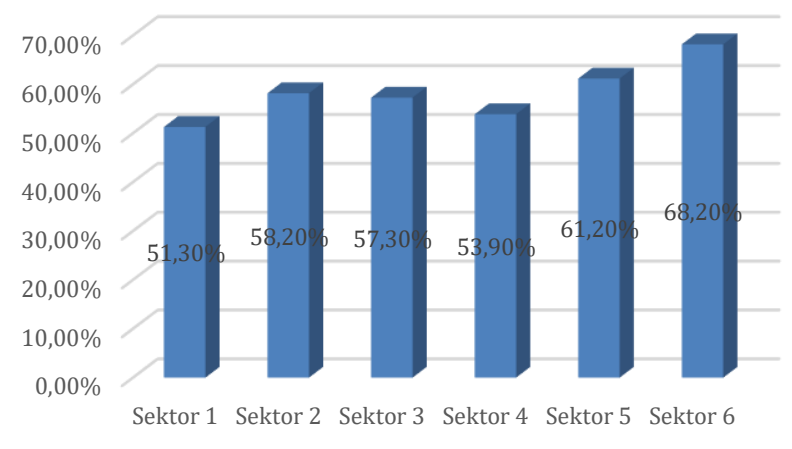

Gambar 2. Persentase Risiko Kebakaran Wilayah Jakarta Utara

Terlihat pada gambar 2, pada sektor 1 sampai dengan 4, memiliki klasifikasi risiko kebakaran sedang, akan tetapi pada sektor 5 dan 6, memiliki klasifikasi risiko kebakaran berat. Nilai rata-rata seluruh sektor Jakarta Utara menjadi 58,34\% dengan klasifikasi risiko kebakaran sedang.

Rincian dari nilai persentase setiap sektor terlihat pada gambar berikut : 


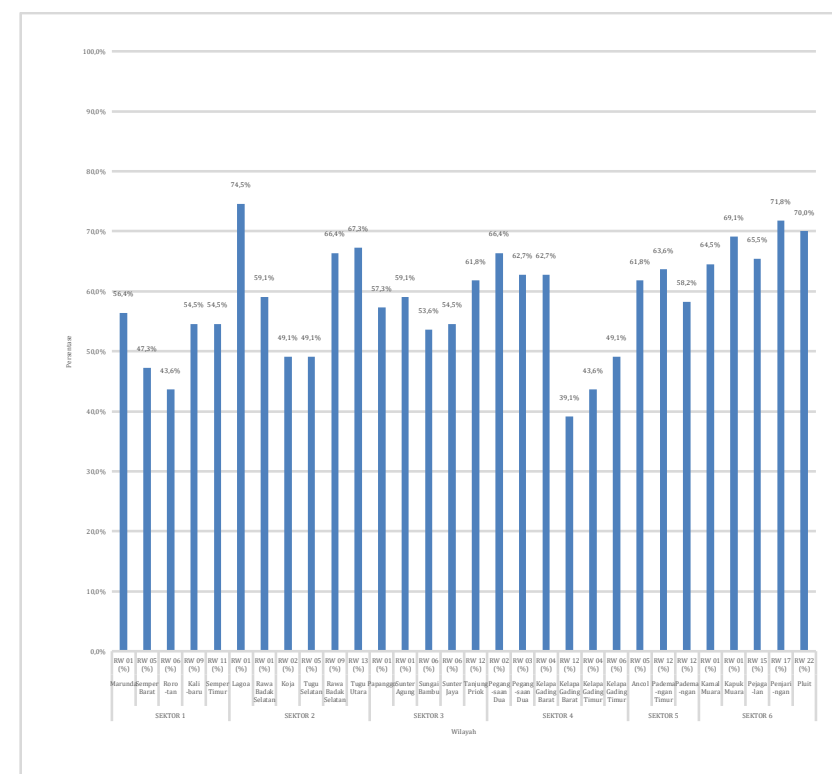

Gambar 3. Rincian Persentase Seluruh Sektor pada Wilayah Jakarta Utara

Detil dari nilai persentase setiap elemen Hazard, Vulnerability serta Manajemen Proteksi Kebakaran dapat terlihat pada gambar berikut ini :

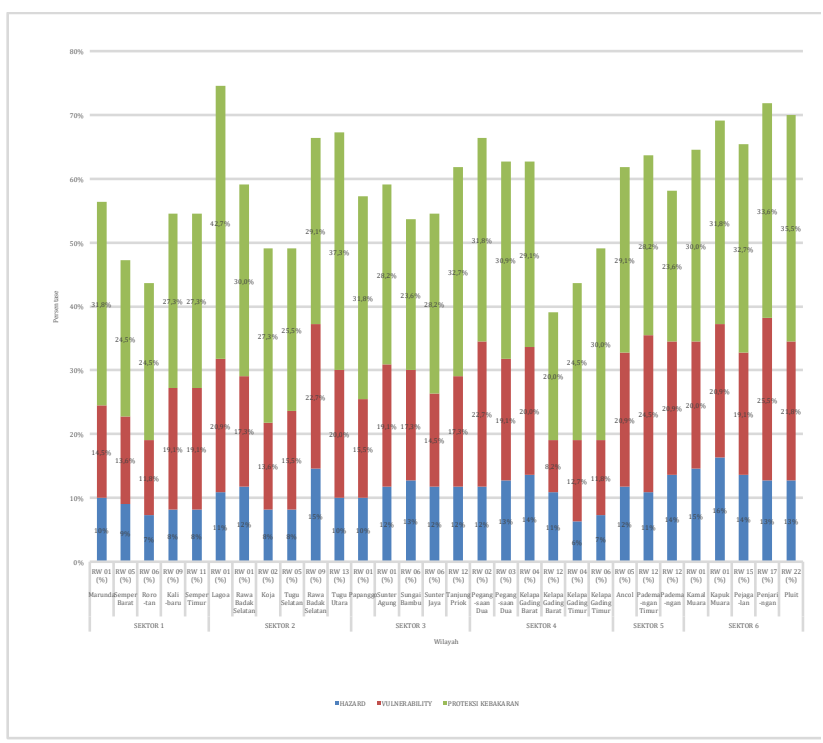

\section{Gambar 4. Nilai Persentase Elemen pada wilayah Jakarta Utara}

Terlihat pada gambar 4 , nilai persentase Sektor 1 untuk elemen hazard antara 7-10\%, elemen vulnerability antara 11,8 -19,1\% dan elemen manajemen proteksi kebakaran antara 24,5-31,8\%. Pada Sektor 2, nilai untuk elemen hazard diantara $8-15 \%$, elemen vulnerability diantara 13,6 - 22,7\% serta nilai elemen manajemen proteksi kebakaran antara 25,5 -
42,7\%. Pada Sektor 3, nilai elemen hazard yaitu $10-12 \%$, elemen vulnerability diantara 14,5 - $19,1 \%$ serta nilai elemen manajemen proteksi kebakaran antara 23,6 - 32,7\%. Pada sektor 4, nilai elemen hazard adalah $6-14 \%$, nilai untuk elemen vulnerability adalah 8,2 $22,7 \%$ serta nilai dari elemen manajemen proteksi kebakaran yaitu diantara $20-31,8 \%$. Pada sektor 5, nilai elemen hazard adalah 11$14 \%$, nilai vulnerability adalah $20,9-24,5 \%$ serta nilai manajemen proteksi kebakaran adalah 23,6 - 29,1\%. Pada sektor 6, nilai elemen hazard diantara $13-16 \%$, nilai elemen vulnerability adalah $19,1-25,5 \%$ serta nilai manajemen proteksi kebakaran adalah $30-$ $35,5 \%$.

Hasil analisis pengamatan pada setiap variabel dari rata-rata wilayah Jakarta Utara terlihat dari tabel berikut ini :

Tabel 1. Skor Rata-rata tingkat potensi bahaya kebakaran berdasarkan 22 variabel wilayah Jakarta Utara

\begin{tabular}{|c|c|c|}
\hline Element & Variabel & $\begin{array}{l}\text { Skor Rata- } \\
\text { Rata }\end{array}$ \\
\hline \multirow[t]{4}{*}{ Fire Hazard } & $\begin{array}{l}\text { Aktivitas warga } \\
\text { yang dapat memicu } \\
\text { reaksi kebakaran }\end{array}$ & 2,5 \\
\hline & Penggunaan listrik & 2,1 \\
\hline & $\begin{array}{l}\text { Penggunaan api } \\
\text { terbuka }\end{array}$ & 2,1 \\
\hline & $\begin{array}{l}\text { Bahan Berbahaya \& } \\
\text { Beracun (B3) }\end{array}$ & 1,9 \\
\hline \multirow[t]{7}{*}{ Vulnerability } & $\begin{array}{l}\text { Kepadatan } \\
\text { penduduk }\end{array}$ & 3,0 \\
\hline & $\begin{array}{l}\text { Kepadatan } \\
\text { bangunan }\end{array}$ & 2,5 \\
\hline & $\begin{array}{l}\text { Kualitas bangunan } \\
\text { \& tingkat } \\
\text { kekumuhan }\end{array}$ & 2,4 \\
\hline & $\begin{array}{l}\text { Frekuensi kejadian } \\
\text { kebakaran }\end{array}$ & 0,8 \\
\hline & $\begin{array}{l}\text { Luas area \& } \\
\text { kerugian }\end{array}$ & 1,1 \\
\hline & $\begin{array}{l}\text { Perambatan api \& } \\
\text { kualitas bangunan }\end{array}$ & 2,2 \\
\hline & $\begin{array}{l}\text { Kendala yang } \\
\text { dihadapi Pos } \\
\text { Damkar }\end{array}$ & 2,1 \\
\hline \multirow{2}{*}{$\begin{array}{l}\text { Fire Protection } \\
\text { and Risk } \\
\text { Management }\end{array}$} & $\begin{array}{l}\text { Jarak Pemisah } \\
\text { Antar Bangunan }\end{array}$ & 3,0 \\
\hline & $\begin{array}{l}\text { Sistem Ketahanan } \\
\text { Kebakaran }\end{array}$ & 2,5 \\
\hline
\end{tabular}




\begin{tabular}{|c|c|c|}
\hline Element & Variabel & $\begin{array}{c}\text { Skor Rata- } \\
\text { Rata }\end{array}$ \\
\hline & $\begin{array}{l}\text { Lingkungan dan } \\
\text { Partisipasi Warga }\end{array}$ & \\
\hline & $\begin{array}{l}\text { Komunikasi } \\
\text { Darurat }\end{array}$ & 1,6 \\
\hline & Pemadaman Dini & 1,5 \\
\hline & $\begin{array}{l}\text { Kelaikan Pos } \\
\text { Damkar }\end{array}$ & 1,6 \\
\hline & $\begin{array}{l}\text { Akses Operasional } \\
\text { Pos Damkar }\end{array}$ & 2,2 \\
\hline & $\begin{array}{l}\text { Waktu Tanggap Pos } \\
\text { Damkar }\end{array}$ & 1,9 \\
\hline & $\begin{array}{l}\text { Layanan Pos } \\
\text { Damkar }\end{array}$ & 1,7 \\
\hline & $\begin{array}{l}\text { Operasional } \\
\text { Pemadaman } \\
\text { Lanjutan dan } \\
\text { Ketersediaan } \\
\text { Sumber Air } \\
\text { Pemadaman }\end{array}$ & 1,7 \\
\hline & $\begin{array}{l}\text { Kemudahan Akses } \\
\text { pemadaman }\end{array}$ & 2,3 \\
\hline & $\begin{array}{l}\text { Kondisi Hidran } \\
\text { Kota }\end{array}$ & 3,2 \\
\hline
\end{tabular}

Skor tertinggi adalah 3,2 pada variabel mengenai kondisi hidran kota yang kurang berfungsi dengan baik sehingga tidak dapat memberikan upaya pemadaman yang maksimal. Selain itu skor tinggi lainnya adalah dengan skor 3 pada variabel jarak pemisah antar bangunan yang cukup sesuai standar yaitu 3-6 meter dan berkorelasi positif dengan tingkat kepadatan penduduk dengan skor 3,0 yang berarti sedang dengan jumlah penduduk 150 - $200 \mathrm{jiwa} / \mathrm{ha}$.

Adapun grafik pemetaan wilayah Jakarta Utara dengan hasil penelitian tersebut sebaagaimana gambar berikut :

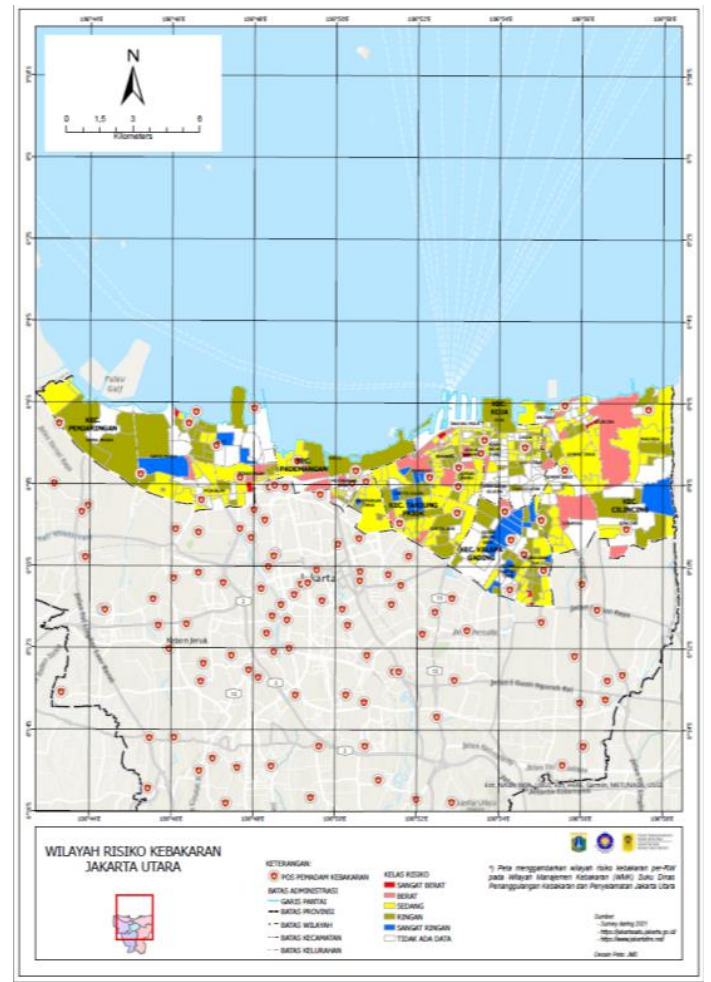

\section{Gambar 6. Pemetaan Risiko Kebakaran Wilayah Jakarta Utara}

\section{PEMBAHASAN}

\section{Gambar 5. Spider Map Tingkat Risiko} Kebakaran Wilayah Jakarta Utara

Berdasarkan tabel 1 dan gambar 5, terlihat bahwa skor yang tinggi menampilkan tingkat potensi kebakaran yang tinggi sedangkan skor rendah menyatakan bahwa tingkat potensi kebakarannya rendah. Skor yang telah baik adalah 0,8 terkait dengan frekuensi kejadian kebakaran yang rendah yang berkorelasi positif dengan hasil kerugian serta luas area terdampak yang rendah dengan nilai 1,1 .

Hasil penelitian dengan skor baik yaitu pada frekuensi kejadian kebakaran yang sangat rendah di setiap sektornya antara 1-2 kali pertahun serta nilai kerugian yang sangat rendah yaitu kurang dari 200 juta rupiah dengan luas area kebakaran kurang dari 100 $\mathrm{m}^{2}$. Hal ini relevan dengan data pada Unit Pengelola Statistik tahun 2020, wilayah Jakarta Utara yang lebih rendah dibandingkan wilayah lainnya (Unit Pengelola Statistik Provinsi DKI Jakarta, 2021). 
Variabel yang perlu adanya peningkatan dan perbaikan adalah pada kondisi hidran yang dipergunakan sebagai sarana pemadaman kebakaran oleh petugas Dinas Pemadam Kebakaran. Nilai skor 3,2 menyatakan bahwa kondisi hidran kota cukup baik akan tetapi masih belum maksimal dilakukan pemeliharaan sehingga terdapat beberapa titik yang tidak berfungsi dengan baik. Hal ini sesuai dengan data wilayah Jakarta Utara dengan total 185 hidran kota, terdapat 75 hidran dalam kondisi rusak dan 110 hidran dalam kondisi baik (Portal Data Terpadu Pemprov DKI Jakarta, 2021). Standar yang digunakan di USA, penempatan hidran kota adalah setiap 152,4 meter atau 500 feet. Tujuan dari pemasangan hidran kota agar mudah diakses dan dapat memberikan upaya pemadaman maksimal serta mempertimbangkan kondisi bangunan serta tidak adanya penghalang antar bangunan $(\mathrm{Wu}$, Z.Y., Song, Y, 2014). Untuk menjamin akses pengoperasian hidran, pemerintah kota melakukan pemastian jalan bebas hambatan terhadap hidran kota sekurang-kurangnya radius $50 \mathrm{~m}$ (PermenPU No. 26 Tahun 2008). Selain itu, secara berkala perlu dilakukan pemastian dan pemeliharaan hidran kota serta pemeriksaan tekanan kerja dengan standar minimum 3,5 bar dan maksimum 5,5 bar harus dijaga pada setiap katup apabila dibuka penuh (SNI 03-1735-2000).

Sebagaimana hasil penelitian selain kondisi hidran kota, hal yang perlu dilakukan perbaikan adalah sosialisasi mengenai pemahaman penggunaan material bangunan yang tidak mudah terbakar. Hal ini tercermin pada hasil skor rata-rata 3,0 pada variabel jarak pemisah antar bangunan serta kepadatan penduduk. Peningkatan kepadatan penduduk dengan tingkat pemahaman mengenai kebakaran rendah serta berada di kondisi dengan fire safety yang buruk maka akan meningkatkan potensi bahaya kebakaran (Zhang Ying et al, 2019). Penggunaan material yang mudah terbakar akan mempercepat waktu perkembangan kebakaran menjadi fase flash over, meningkatkan kecepatan perambatan api dan memberikan pengaruh terhadap manusia dalam waktu singkat
(Wahyu Sujatmiko et al, 2016). Salah satu langkah strategis penanggulangan kebakaran yang efektif pada daerah perkotaan dengan kepadatan penduduk maupun kerapatan bangunan tinggi adalah dengan perancangan sistem pendeteksi kebakaran pada rumah tinggal yang bekerja secara otomatis saat kebakaran terjadi. Sistem ini berbasis mikrokontroler dan mendeteksi secara cepat dengan mengetahui lokasi kebakaran melalui sensor suhu dan sensor asap serta memanfaatkan aplikasi mobile dan web (Dodon Yendri, Wildian, Amalia Tiffany, 2017).

\section{KESIMPULAN}

Hasil penelitian wilayah Jakarta Utara mendapatkan klasifikasi tingkat risiko kebakaran Sedang dengan nilai sebesar $58,34 \%$. Variabel dengan skor tertinggi adalah kondisi hidran kota yang kurang berfungsi dengan baik serta kepadatan penduduk dengan jarak pemisah antar bangunan tempat tinggal yang rapat sehingga dapat memicu penjalaran api lebih cepat. Rekomendasi perbaikan yang dapat dilakukan oleh Dinas Pemadam Kebakaran wilayah Jakarta Utara adalah pelaksanaan pemeliharaan dan pemeriksaan kondisi hidran kota secara berkala serta sosialisasi mengenai penggunaan material tidak mudah terbakar untuk bangunan. Selain itu dapat dilakukan perancangan sistem berbasis mikrokontroler untuk mempercepat pendeteksian kebakaran melalui aplikasi mobile dan web. Hal ini dapat meningkatkan waktu kerja petugas pada Dinas Pemadam Kebakaran serta memberikan peringatan awal kepada warga apabila terjadi kebakaran di wilayahnya.

\section{UCAPAN TERIMAKASIH}

Kami berterimakasih kepada Dinas Penanggulangan Kebakaran dan Penyelamatan Provinsi DKI Jakarta serta Suku Dinas Penanggulangan Kebakaran dan Penyelamatan Kota Administrasi Jakarta Utara yang telah berpartisipasi pada penelitian ini. Penelitian ini didukung oleh Universitas 
Indonesia Research Grant Number : NKB576/UN2.RST/HKP.05.00/2021.

\section{DAFTAR PUSTAKA}

Ahrens, M., Maheshwari, R. (2020). Home Structure Fires. Quincy, MA. National Fire Protection Association.

Dodon Yendri, Wildian, Amalia Tiffany. (2017). Perancangan Sistem Pendeteksi Kebakaran Rumah Penduduk Pada Daerah Perkotaan Berbasis Mikrokontroler. Jurnal Fakultas Teknik Universitas Muhammadiyah Jakarta.

Luo, Y., Li, Q., Jiang, Lian., Zhou, Y. (2021). Analysis of Chinese fire statistics during the period 1997-2017. Fire Safety Journal, Volume 125, ISSN 0379-7112, https://doi.org/10.1016/j.firesaf.2021.103 400

Natalia Flores Quiroz, Richard Walls, Antonio Cicione. (2021). Developing a framework for fire investigations in informal settlements. Fire Safety Journal. https://doi.org/10.1016/j.firesaf.2020.103 046

Peraturan Menteri Pekerjaan Umum dan Perumahan Rakyat No. 26/PRT/M/2008 tentang Persyaratan Teknis Sistem Proteksi Kebakaran pada Bangunan Gedung dan Lingkungan. Jakarta

Portal Data Terpadu Pemprov DKI Jakarta (2021). Data Jumlah Peristiwa Kebakaran Menurut Bulan dan Kabupaten Kota Di Provinsi DKI Jakarta Tahun 2020 - Open Data Jakarta, accessed on July 17, 2021.

Portal Data Terpadu Pemprov DKI Jakarta (2021). Data Jumlah Peristiwa Kebakaran Menurut Bulan dan Kabupaten Kota Di
Provinsi DKI Jakarta Tahun 2019 - Open Data Jakarta accessed on July 17, 2021.

Portal Data Terpadu Pemprov DKI Jakarta (2021). Data Jumlah Hidran Di Provinsi DKI Jakarta Tahun 2020 - Open Data Jakarta, accessed on July 17, 2021.

Standar Nasional Indonesia (SNI) No. 03-17352000 tentang Tata Cara Perencanaan Akses Bangunan dan Akses Lingkungan untuk Pencegahan Bahaya Kebakaran pada Bangunan Gedung. Jakarta

Unit Pengelola Statistik DKI Jakarta (2021). Kejadian Kebakaran di DKI Jakarta Tahun 2020 - Unit Pengelola Statistik, accessed on July 17, 2021.

Undang-Undang No. 24 Tahun 2007 tentang Penanggulangan Bencana. Jakarta

Wahyu Sujatmiko et al. (2016). Study on fire dynamic development in a multistory building compartment. Science Direct.

Wu, Z.Y., Song, Y. (2014). Optimizing Selection of Fire Hydrants for Flow Tests in Water Distribution Systems. Procedia Engineering. Volume 70: Pages 17451752. ISSN 1877-7058, https://doi.org/10.1016/j.proeng.2014.02. 192

Zhang, Ying et al. (2019). How fire safety management attended during the urbanization process in China?. Journal of Cleaner Production. Volume 236. ISSN 0959-6526. https://doi.org/10.1016/j.jclepro.2019.117 686. 